\title{
The effect of pomegranate seed oil on human health, especially epidemiology of polycystic ovary syndrome; a systematic review
}

\author{
Mahmoud Bahmani ${ }^{1}$, Samira Shokri ${ }^{2}$, Zabih Nosrati Akhtar ${ }^{3}$, Saber Abbaszadeh ${ }^{4}$, Aliasghar Manouchehri ${ }^{5}$
}

\author{
${ }^{1}$ Biotechnology and Medicinal Plants Research Center, Ilam University of Medical Sciences, Ilam, Iran \\ ${ }^{2}$ Department of Environmental Health Engineering, Division of Food Safety \& Hygiene, School of Public Health, \\ Tehran University of Medical Sciences, Tehran, Iran \\ ${ }^{3}$ Boroujerd Branch, Islamic Azad University, Boroujerd,Iran \\ ${ }^{4}$ Department of Biochemistry and Genetics, School of Medicine, Lorestan University of Medical Sciences, \\ Khor-ramabad, Iran \\ ${ }^{5}$ Department of Internal Medicine, Shahid Beheshti Hospital, Babol University of Medical Sciences, Babol, Iran
}

\begin{abstract}
Polycystic ovary syndrome is the most common endocrine disorder in women. Today, medicinal plants have been considered by women, especially in the reproductive and pregnancy ages. Multiple drug treatments and the length of the treatment period often lead to incomplete treatment by patients. Therefore, due to the side effects of chemical drugs, this study was conducted to assess investigate the effect of pomegranate seed oil on polycystic ovary syndrome. The prevalence of polycystic ovary syndrome is increasing by 15 to $20 \%$ and clinically includes oligomenorrhea or amenorrhea, hirsutism, and often infertility. Databases such as Cochran library, Medline, PubMed, SID, and Science Direct were used to access the related articles. To collect the required information, first, the articles that had one of the keywords of medicinal plants, polycystic ovary syndrome, plant, pomegranate extract, and menstrual irregularities in their text were searched in databases. All studies from 1985 to 2021 are included in the study. Conjugated linolenic acid (CLN) is a group of geometric and positional isomers of linolenic acid in which double bonds are conjugated. CLN has been reported to have a very strong cytotoxic effect on tissue tumor cells in the body, preventing cancer, reducing the accumulation of triacylglycerol in the liver, polycystic ovary syndrome, and LDL cholesterol in the blood. So far, seven CLN isomers have been identified, including ponic acid in pomegranate seed oil. Conjugated linoleic acid (CLA) is a group of situational and geometric isomers of linoleic acid in which double bonds are conjugated. The positive effects of the two main CLA isomers (cis-9, trans-11, and trans-10, cis-12) include inhibiting the growth of cancer, reducing the risk of atherosclerosis, and reducing body fat.
\end{abstract}

Keywords: pomegranate seed oil, polycystic ovary syndrome, effects, epidemiology, health, linolenic acid, linoleic acid

\section{INTRODUCTION}

Polycystic ovary syndrome (PCOS) is the most common endocrine disorder and metabolic heterogeneity in women of childbearing age. It involves various factors involved influenced by environmental factors such as eating habits, lifestyle, and social status (Beydoun et al., 2009). The most important feature of this disorder is the presence of large ovaries containing a large number of small cysts that are located in the outer layer of each ovary. In this syndrome, the levels of female hormones (such as estrogen, progesterone) become unbalanced and cause an increase in male hormones (androgens) and insulin. This causes symptoms such as menstrual irregularities, hair loss, acne, infertility, and obesity (Goodarzi et al., 2012; Wang et al., 2011).

Epidemiological studies show that the prevalence of PCOS varies from 2.2-26\% in different countries (March et al., 2010; Tehrani et al., 2011). In Brazil, the prevalence of PCOS in women aged $18-45$ years was estimated at $8.5 \%$ (Gabrielli \& Aquino, 2012) and in Italy in adolescents aged 18 years 32\% (Franceschi et al., 2010). Various treatments have been proposed for polycystic ovary syndrome; such as lifestyle changes, surgery, and the use of chemical drugs that today the use of medicinal plants, has been significantly considered by researchers due to the side effects and risks of chemical drugs, especially in mothers of childbearing age (Ortmann et al., 2002). Pomegranate is one of the fruits that is widely consumed all over the world and has been of considerable importance in the pharmaceutical and food industries.

Pomegranate is a fruit-bearing deciduous shrub or small Asian tree with the scientific name of Punica granatum, which reaches a height of 5 to 8 meters. This plant is native to Iran and northern India and has long been cultivated in the Mediterranean region. This plant is currently widely cultivated throughout Armenia, Iran, India, South Asia, East India, and tropical Africa. Pomegranate is a drought-tolerant plant that can grow in arid areas with the Mediterranean climate, winter rainfall, or summer rainy climate. In Iran, pomegranates are grown mainly in desert areas with hot and dry summers, scorching suns, relatively cold winters, and salty soil and water; this wide range of adaptation is one of the desirable characteristics of pomegranate ecophysiology. Pomegranate fruit has a thin leathery skin that changes color from red to pinkish yellow. The kernels are edible and are covered with a fleshy, transparent, and white to a red color called aryl with a sour-sweet taste. Pomegranate kernels make an average of 143-37 grams per kilogram of pomegranate fruit, kernels are rich in oil and about $12-18 \%$ of it is oil (Radjabian et al., 2008). The pomegranate seed oil )PSO) contains a variety of fatty acids, about $80 \%$ of which are 18 -carbon fatty acids with three conjugated double bonds 
(punic acid). Studies have shown that ponic acid is physiologically much stronger than Conjugated linoleic acid )CLA( (Mukherjee et al., 2002).

There are very few reports on the pharmacological effects of PSO. A study by Nikseresht et al. (2015) showed that PSO had a positive effect on the fertilization power of male rats. These effects can be helpful for infertility. PSO supplementation may reduce oxidative stress in sperm and increase the pregnancy rate in women. In one study, pomegranate seed extract probably played an important role in reducing postpartum hemorrhage in mice (Hossein et al., 2015). A grape seed extract has probably increased the number of ovarian follicles and the formation of corpus luteum in the polycystic ovary due to its antioxidant and anti-inflammatory properties (Salmabadi et al., 2017).

In a study by Arao et al. (2004), the effect of punic acid-rich PSO on fat metabolism in high-cholesterol mice was investigated. The results showed that feeding mice with PSO significantly reduced the accumulation of triglycerides and monounsaturated fatty acids in their liver. PSO prevents breast cancer due to its phytoestrogens and is also used in medicinal products effective in preventing skin aging.

Pomegranate seed oil and juice is a synthetic antioxidant with carcinogenic properties. For this reason, in recent years, much attention has been paid to the replacement of natural antioxidants, especially in plant sources. Due to the lack of data on the possible effect of pomegranate seed water and oil consumption on patients with polycystic ovary syndrome, this study aimed to investigate the effect of pomegranate seed oil on human health.

\section{METHODS}

A complete the databases searched for in those articles were "Google Scholar", "SID", "Scopus", "PubMed", "Science Direct", and "ISI" search engines. The search was done for articles published that included the search the effect of pomegranate seed oil on human health in their title. This study focused on published articles papers from 1985 to 2021.

\section{RESULTS AND DISCUSSION}

\section{Lipids and their types}

Lipids are a wide range of substances that are generally soluble in organic solvents and insoluble in water. The terms fat and oil are two functional equivalents for lipids that are sometimes used interchangeably. But in general, fat can be considered a type of lipid that is solid at room temperature, while the term oil is used for liquid lipids at room temperature (Nichols \& Sanderson, 2002). In the human body, saturated and monounsaturated fatty acids are synthesized from acetyl coenzyme A or obtained from diets. In contrast, some fatty acids, such as linoleic acid and linolenic acid, are not synthesized by humans due to a lack of necessary enzymes and must be supplied through food, which is why these compounds are called essential fatty acids (EFA). These fatty acids are part of omega- 3 and omega- 6 fatty acids, which make up onethird of intracellular fatty acids. Essential fatty acids are also involved in the structure of phospholipids, which play a role in cellular structure, and when phospholipids are deficient, energy metabolism is disrupted. Essential fatty acids also lower cholesterol, so their presence or the ratio of essential fatty acids to saturated fatty acids is a factor in lowering blood cholesterol (Sikorski \& Kolakowska, 2002). A proper balance between the number of lipids in the diet and its nutritional quality is very important in maintaining human health. Today, it has been proven that some fats and oils in the human body have beneficial properties and in addition to having nutritional value, they can also have positive effects on human health. These compounds are called functional Lipid, Nutritional Lipid, It is called Medical Lipid or Pharmaceutical Lipid. For this reason, the food industry, considering the increasing awareness of people about nutrition and health issues, is trying to introduce such products to the consumer and meet the needs of the market by producing such products (Adhikari et al., 2010).

\section{Conjugated Linolenic Acid (CLN)}

A conjugated linolenic acid is a group of geometric and positional isomers of linolenic acid in which double bonds are conjugated. CLN isomers are found in the oils of certain plant seeds and often as the major fatty acid.

So far, seven CLN isomers have been identified, including Eleostearic Acid (ESA-a) in Bitter Melon seed oil, Punicic Acid (PA) in pomegranate seed oil, Catalpic Acid in Jacaric Acid seed oil, and Jacaranda mimosifolia in pomegranate seed oil (Adhikari et al., 2010).

\section{Effects of CLN on human health \\ The effect of pomegranate seed oil on polycystic ovary syndrome}

PCOS is the most common endocrine or endocrine disorder in women and the cause of infertility due to ovulation, which affects different aspects of people's lives due to different symptoms. This syndrome occurs in $10-15 \%$ of girls and women. Manifestations of this syndrome include hirsutism, hyperandrogenism, acne, endometrial thinning, menstrual disorders, and obesity (Makker et al., 2012; Moradi \& Darvishi, 2009; Yildirim et al., 2003).

In recent years, many studies were done on the use of herbal medicines in the treatment of polycystic ovary syndrome. Changes in sex hormone levels are important in polycystic ovary syndrome, and serum concentrations of testosterone and androstenedione are 50 to $150 \%$ higher in women with PCOS than in normal women (Attarzadeh et al., 2012). In a study by Hossein et al. (2015) the use of pomegranate extract improved changes in female sex hormones in patients with PCOS. Therefore, it was suggested that this extract be used to reduce the symptoms of PCOS.

Esmaeilinezhad et al. (2019) examined the effect of synbiotic pomegranate juice on blood glucose indices, sex hormone profile, and anthropometric indices in polycystic ovary syndrome, the results showed that testosterone levels, BMI, and weight were significantly reduced. Shamsi et al. (2016) showed that Glycyrrhiza glabra extract reduces serum levels of testosterone and estrogen in the study of the effect of glycyrrhizic acid on ovarian tissue follicles in mice with polycystic ovaries.

Serological changes of curcumin were also observed in the form of increased FSH and progesterone, decreased $\mathrm{LH}$, estradiol, and testosterone (Nabiuni et al., 2015) by $18 \%$ and $23 \%$ (and reduced progesterone (Mokhtari et al., 2014). Phenolic compounds similar to pomegranate extract show positive effects in improving the complications of PCOS (Milewicz et al., 1993). Evaluation of the role of possible improvement of pomegranate juice extracts on endometrial damage in a rat model with endometrial histological changes through antioxidant, anti-inflammatory, and anti-fibrotic effects, due to its polyphenol content (Ibrahim et al., 2021). Study by Fozalaee et al. (2015) and Pahlevani et al. (2016) examined the effect of fennel extract and Stachys lavandulifolia on uterine tissue structure in mice with PCOS, respectively. Kouchesfahani et al. (2010) in a study showed that honey bee venom with 
antioxidant and anti-inflammatory effects in polycystic ovary affected rats increased the number of small follicles and the appearance of corpus luteum in the ovary.

Free radicals are responsible for membrane lipid peroxidation, decreased sperm motility, and sperm inability to fertilize eggs (Gil-Guzman et al., 2001). Pomegranate juice contains vitamins $C$ and $E$, which play an important role in targeting free radicals (Sönmez et al., 2005; 2007). The effect of pomegranate extract on sperm parameters, fertility potential in mice, and improving sperm parameters are effective and its administration is recommended to improve the sperm status of infertile men because it is herbal and available (Amini Rad et al., 2009).

\section{Anti-cancer properties}

According to reports, CLN has a very strong cytotoxic effect on tumor tissue cells in the body and prevents coIon and skin cancer in mice and a rapid increase in breast cancer cells in humans (Eikani et al., 2012). Kohno et al. (2004) fed rats with diets of different concentrations of pomegranate seed oil, studied the effects of conjugated linolenic acid on the prevention of colon cancer and found that pomegranate seed oil, due to its rich CLN fatty acid content, could Prevent the formation of colon cancer cells.

\section{Anti-atherosclerosis}

Arao et al. (2004) reported that linolenic acid affected on the indicated that by feeding a diet enriched with pomegranate seed oil in rats, they observed positive effects of ponic acid on liver triglyceride levels.

\section{Anti-atherosclerotic properties}

Cardiovascular disease caused by high blood lipid levels is a very common problem that has led to many deaths. Studies show that changing lifestyle habits such as eating habits, exercising, and avoiding smoking can help prevent these diseases (Marcus et al., 1999; Ross, 2000). Diet plays a major role in reducing the risk of cardiovascular disease, and extensive research on specific foods and components has shown that improving the incidence of serum lipids can reduce the incidence of these diseases (Duthie \& Brown, 1994; Kannel, 1985). Radjabian et al. (2008) showed that the progression of atherosclerosis in the aorta of rabbits in the group treated with pomegranate seed oil was significantly reduced compared to the control group. Mukherjee et al. (2002) examined the effect of different concentrations of Punicic Acid (0.6, 2.1, 4.2\%) on laboratory mice. Finally, a significant reduction in plasma cholesterol and LDL levels was observed in the group treated with $2.4 \%$ Punicic Acid.

\section{Conjugated Linoleic Acid}

CLA is a general term for all positional and geometric isomers of linoleic acid conjugated DNA. Linoleic acid, or 9-cis, 12-cis octoic acid, is an 18-carbon double-bonded fatty acid in positions 9 and 12 . All known physiological effects of CLA are related to only the two major isomers of CLA, t11 and t10, c12. The main sources of CLA are naturally ruminant animal fats. Milk and dairy products have the highest amount of CLA. The CLA levels in some foods are shown in Table 1 . Among meat products, ruminant meat has higher levels of CLA than non-ruminant meat. The highest amount of CLA in meat products is found in mutton. Vegetable oils and margarine also contain a very small amount of CLA (0.1-0.5 mg per gram of fat), which is the result of industrial processes such as oil refining (especially the roasting step) and the hydrogenation process. In addition, CLA can be produced in oil due to high heat processes, for example, sunflower oil after use for frying contains 0.5 grams of CLA per 100 grams of oil (Wahle et al., 2004; Gnädig et al., 2003).

\section{Effects of linoleic acid on human health} Reduce body fat

Today, obesity is an important factor in the development of heart disease, diabetes, and high blood pressure. The first report on CLA's ability to reduce body fat in a rat treatment was published in 1995 . In that study, it was found that using CLA at a rate of $0.5 \%$ in the diet reduces body fat and increases the amount of protein and water. In 1999, it was discovered that this CLA effect was related to the isomers t10, c12 (Wahle et al., 2004; Park \& Pariza, 2007). In another study, it was found that the supplementation of CLA isomers (concentration of both isomers C9, t11 and t10, c12 in the mixture was $50 \%$ ) by 3 grams per day, the plasma triglyceride concentration is rapidly reduced. The ability of CLA to alter lipid metabolism depends on factors such as increased lipolysis rate and fatty acid oxidation and decreased cellular fatty acid uptake.

The effect of CLA on reducing body fat in humans was less than in mice, which could be due to the following reasons: (Franceschi et al., 2010) The dose of CLA used in humans was much lower than the dose used in mice. Mice were fed a diet containing ( $w / w$ ) $0.5 \%$ CLA, which is equivalent to 56 grams of CLA per $70 \mathrm{~kg}$ individual. While the dose of CLA for humans in various studies was between 0.7-6.8 grams per day, which is much lower than the estimated 56 grams (Goodarzi et al., 2012). Different responses to CLA in humans and mice may be due to differences in their fat metabolism. In general, to accurately identify the mechanism of action of CLA in reducing body fat and its effects, more studies and research are needed.

\section{Antioxidant properties}

Changing the profile of fatty acids in cancer cells and interfering with the production of eicosanoids.

The effect on the growth and increase of certain types of cancer cells and Apoptosis (Ha et al., 1990).

\section{Anti-atherosclerotic property}

Oxidative stress is one of the main causes of atherosclerosis. LDL oxidation is a well-known mechanism in this regard. Evidence suggests that the disease can be cured or controlled with antioxidants. As mentioned, the antioxidant properties of CLA have been proven in many studies (Flintoff-Dye \& Omaye, 2005). Kostogrys \& Pisulewski (2010) investigated the effect of CLA oil on a high-fructose diet in Wistar rats and concluded that CLA in this type of diet reduces plasma triglycerides and LDL.

\section{Acknowledgments}

The authors thank the Tehran University of Medical Sciences, Tehran, Iran who helped in this study.

\section{Funding}

This research was not funded.

\section{CONFLICT OF INTEREST}

There is not any conflict of interest.

\section{Corresponding author:}

Aliasghar Manouchehri

Babol University of Medical Sciences

Babol, Iran

E-mail:drmanouchehri@yahoo.com 


\begin{tabular}{|l|c|c|}
\hline Table 1. Conjugated linoleic acid (CLA) levels in some foods (Wahle et al., 2004). \\
\hline Food & CLA rate \% & Percentage of isomer c9, t1 \\
\hline Milk & 5.5 & 92 \\
\hline Butter & 4.7 & 98 \\
\hline Sour cream & 4.6 & 84 \\
\hline Yogurt & 4.8 & 86 \\
\hline Ice cream & 3.6 & 93 \\
\hline Cheddar cheese & 3.6 & 95 \\
\hline Mozzarella cheese & 4.9 & 85 \\
\hline Fresh beef & 3.4 & 92 \\
\hline Lamb meat & 5.6 & 84 \\
\hline Veal & 2.7 & 84 \\
\hline Chicken & 0.9 & 76 \\
\hline Turkey meat & 2.5 & 38 \\
\hline Sunflower oil & 0.4 & \\
\hline Safflower oil & 0.7 & \\
\hline Canola oil & 0.5 & \\
\hline Corn oil & 0.2 & \\
\hline
\end{tabular}

\section{REFERENCES}

Adhikari P, Zhu XM, Gautam A, Shin JA, Hu JN, Lee JH, Akoh CC, Lee KT. Scaled-up production of zero-trans margarine fat using pine nut oil and palm stearin. Food Chem. 2010;119:1332-8. DOI: 10.1016/j.foodchem.2009.09.009

Amini Rad O, Khalili MA, Soltani Gord Faramarzi HR. Influence of pomegranate juice on sperm parameters and fertility in mice. Hormozgan Med J. 2009;13:182-8.

Arao K, Wang YM, Inoue N, Hirata J, Cha JY, Nagao K, Yanagita T. Dietary effect of pomegranate seed oil rich in 9 cis, 11 trans, 13 cis conjugated linolenic acid on lipid metabolism in obese, hyperlipidemic OLETF rats. Lipids Health Dis. 2004;3:24. PMID: 15533261 PMID: 15533261 DOI: 10.1186/1476-511X-3-24

Attarzadeh R, Sardar MA, Taghavi M, Ayaz Khosh Hava F. The effects of an aerobic exercise program on $\mathrm{LH}, \mathrm{FSH}$, TST and DHEA levels in obese women. Iran J Endocrinol Metab. 2012;14:39-46.

Beydoun HA, Stadtmauer L, Beydoun MA, Russell H, Zhao $Y$, Oehninger S. Polycystic ovary syndrome, body mass index and outcomes of assisted reproductive technologies. Reprod Biomed Online. 2009;18:856-63. PMID: 19490792 DOI: $10.1016 / S 1472-6483(10) 60037-5$

Duthie GG, Brown KM. Reducing the Risk of Cardiovascular Disease. In: Goldberg I, ed. Functional Foods. Boston: Springer; 1994.

Eikani $\mathrm{MH}$, Golmohammad $\mathrm{F}$, Homami SS. Extraction of pomegranate (Punica granatum L.) seed oil using superheated hexane. Food Bioprod Process. 2012;90:32-6. DOI: $10.1016 /$ j.fbp.2011.01.002
Esmaeilinezhad Z, Babajafari S, Sohrabi Z, Eskandari $\mathrm{MH}$, Amooee S, Barati-Boldaji R. Effect of synbiotic pomegranate juice on glycemic, sex hormone profile and anthropometric indices in PCOS: A randomized, triple blind, controlled trial. Nutr Metab Cardiovasc Dis. 2019;29:201-8. PMID: 30538082 DOI: 10.1016/j.numecd.2018.07.002

Flintoff-Dye NL, Omaye ST. Antioxidant effects of conjugated linoleic acid isomers in isolated human low-density lipoproteins. Nutr Res. 2005;25:1-12. DOI: 10.1016/j.nutres.2004.10.003

Fozalaee SS, Farokhi F, Khaneshi F. The effect of metformin and aqueous extract Foeniculum vulgare (fennel) on endometrial histomorphometry and the level of steroid hormones in rats with polycystic ovary syndrome. Qom Univ Med Sci J. 2015;8:12-9.

Franceschi R, Gaudino R, Marcolongo A, Gallo MC, Rossi L, Antoniazzi F, Tatò L. Prevalence of polycystic ovary syndrome in young women who had idiopathic central precocious puberty. Fertil Steril. 2010;93:1185-91. PMID: 19135667 DOI: 10.1016/j. fertnstert.2008.11.016

Gabrielli L, Aquino EM. Polycystic ovary syndrome in Salvador, Brazil: a prevalence study in primary healthcare. Reprod Biol Endocrinol. 2012;10:96. PMID: 23173761 DOI: 10.1186/1477-7827-10-96

Gil-Guzman E, Ollero M, Lopez MC, Sharma RK, Alvarez JG, Thomas AJ Jr, Agarwal A. Differential production of reactive oxygen species by subsets of human spermatozoa at different stages of maturation. Hum Reprod. 2001;16:1922-30. PMID: 11527899 DOI: 10.1093/ humrep/16.9.1922 
Gnädig S, Xue Y, Berdeaux O, Chardigny JM, Sebedio JL. Conjugated linoleic acid (CLA) as a functional ingredient. In: Mattila-Sandholm T, Saarela M, eds. Functional Dairy Products. Cambridge: Woodhead Publishing; 2003. p. 263-97.

Goodarzi MO, Jones MR, Li X, Chua AK, Garcia OA, Chen YD, Krauss RM, Rotter JI, Ankener W, Legro RS, Azziz R, Strauss JF 3rd, Dunaif A, Urbanek M. Replication of association of DENND1A and THADA variants with polycystic ovary syndrome in European cohorts. J Med Genet. 2012;49:90-5. PMID: 22180642 DOI: 10.1136/jmedgenet-2011-100427

Ha YL, Storkson J, Pariza MW. Inhibition of benzo(a) pyrene-induced mouse forestomach neoplasia by conjugated dienoic derivatives of linoleic acid. Cancer Res. 1990;50:1097-101. PMID: 2297758

Hossein KJ, Leila KJ, Ebrahim TK, Nazanin SJ, Farzad P, Elham R, Mohammad $\mathrm{P}$, Zahra HJ. The effect of pomegranate juice extract on hormonal changes of female Wistar rats caused by polycystic ovarian syndrome. Biomed Pharmacol J. $2015 ; 8: 971-7$. DOI: $10.13005 / \mathrm{bpj} / 849$

Ibrahim MAA, Sadek MT, Sharaf Eldin HEM. Role of pomegranate extract in restoring endometrial androgen receptor expression, proliferation, and pinopodes in a rat model of polycystic ovary syndrome. Morphologie. 2021:S12860115(21)00067-9. Epub ahead of print. PMID: 34023214 DOI: $10.1016 /$ j.morpho.2021.04.004

Kannel WB. Lipids, diabetes, and coronary heart disease: insights from the Framingham Study. Am Heart J. 1985;110:1100-7. PMID: 4061265 DOI: 10.1016/00028703(85)90224-8

Kohno H, Suzuki R, Yasui Y, Hosokawa M, Miyashita K, Tanaka T. Pomegranate seed oil rich in conjugated linolenic acid suppresses chemically induced colon carcinogenesis in rats. Cancer Sci. 2004;95:481-6. DOI: $10.1111 / j .1349-$ 7006.2004.tb03236.x

Kostogrys RB, Pisulewski PM. Effect of conjugated linoleic acid (CLA) on lipid profile and liver histology in laboratory rats fed high-fructose diet. Environ Toxicol Pharmacol. 2010;30:245-50. PMID: 21787656 DOI: 10.1016/j. etap.2010.06.006

Kouchesfahani HM, Nabyooni M, Adham H. Investigating the therapeutic effect of bee venom on polycystic ovarian syndrome in rats. Pejouhandeh. 2010;15:1-6.

Makker A, Goel MM, Das V, Agarwal A. PI3K-Akt-mTOR and MAPK signaling pathways in polycystic ovarian syndrome, uterine leiomyomas and endometriosis: an update. Gynecol Endocrinol. 2012;28:175-81. PMID: 21916800 DOI: 10.3109/09513590.2011.583955

March WA, Moore VM, Willson KJ, Phillips DI, Norman RJ, Davies MJ. The prevalence of polycystic ovary syndrome in a community sample assessed under contrasting diagnostic criteria. Hum Reprod. 2010;25:544-51. PMID: 19910321 DOI: 10.1093/humrep/dep399
Marcus BH, Albrecht AE, King TK, Parisi AF, Pinto BM, Roberts M, Niaura RS, Abrams DB. The efficacy of exercise as an aid for smoking cessation in women: a randomized controlled trial. Arch Intern Med. 1999;159:1229-34. PMID: 10371231 DOI: $10.1001 /$ archinte.159.11.1229

Milewicz A, Gejdel E, Sworen H, Sienkiewicz K, Jedrzejak J, Teucher T, Schmitz H. Vitex agnus castus extract in the treatment of luteal phase defects due to latent hyperprolactinemia. Results of a randomized placebo-controlled double-blind study. Arzneimittelforschung. 1993;43:7526. PMID: 8369008

Mokhtari M, Ebrahimpoor MR, Harfsheno S. The effects of alcoholic extract of Marrubum vulgare on hormonal parameters in female rat model of polycystic ovarian syndrome. Med Sci. 2014;24:74-80.

Moradi S, Darvishi N. Evaluation of the Prevalence of Metabolic Syndrome in Women with Polycystic Ovary Syndrome Referred to the Institute of Endocrine and Metabolism. Razi J Med Sci. 2009;16.

Mukherjee C, Bhattacharyya S, Ghosh S, Bhattacharyya DK. Dietary effects of punicic acid on the composition and peroxidation of rat plasma lipid. J Oleo Sci. 2002;51:51322. DOI: $10.5650 /$ jos. 51.513

Nabiuni M, Mohammadi S, Kayedpoor P, Karimzadeh L. The effect of curcumin on the estradiol valerate-induced polycystic ovary in rats. Feyz. 2015;18:515-23.

Nichols DS, Sanderson K. The Nomenclature, Structure, and Properties of Food Lipids. In: Sikorski ZE, Kolakowska A, eds. Chemical and Functional Properties of Food Lipids. Boca Raton: CRC Press; 2002. p. 29-60.

Nikseresht M, Fallahzadeh AR, Toori MA, Mahmoudi R. Effects of Pomegranate Seed Oil on the Fertilization Potency of Rat's Sperm. J Clin Diagn Res. 2015;9:FF01-4. PMID: 26816914 DOI: $10.7860 / J C D R / 2015 / 12576.6853$

Ortmann O, Weiss JM, Diedrich K. Gonadotrophin-releasing hormone (GnRH) and GnRH agonists: mechanisms of action. Reprod Biomed Online. 2002;5:1-7. PMID: 12537774 DOI: $10.1016 / \mathrm{S} 1472-6483(11) 60210-1$

Pahlevani P, Mosavi SM, Rastgoo Haghi AR, Lahotian $H$, Esna Ashari F, Alizadeh Z. Study of the effects of stachys Ivandulifolia alcoholic extract on histomorphometry of endometrium in polycystic ovarian syndrome rat model. Avicenna J Clin Med. 2016;23:40-8.

Park Y, Pariza MW. Mechanisms of body fat modulation by conjugated linoleic acid (CLA). Food Res Int. 2007;40:31123. DOI: $10.1016 / j$.foodres.2006.11.002

Radjabian T, Fallah Husseini H, Karami M, Rasooli I, Faghihzadeh S. Effect of Pomegranate Fruit Juice and Seed Oil on Serum Lipid Levels and Atherosclerosis Development in Hypercholesterolemic Rabbits. J Med Plants. 2008;7:93104. 
Ross CE. Walking, exercising, and smoking: does neighborhood matter? Soc Sci Med. 2000;51:265-74. PMID: 10832573 DOI: $10.1016 / S 0277-9536(99) 00451-7$

Salmabadi Z, Mohseni Kouchesfahani H, Parivar K, Karimzadeh L. Effect of Grape Seed Extract on Lipid Profile and Expression of Interleukin-6 in Polycystic Ovarian Syndrome Wistar Rat Model. Int J Fertil Steril. 2017;11:17683. PMID: 28868839 DOI: $10.22074 /$ ijfs.2017.5007

Shamsi M, Nejati V, Najafi G. Therapeutic effects of Licorice extract on in vitro maturation and in vitro fertilization in Mice model of polycystic ovary syndrome. J Mazandaran Uni Med Sci. 2016;25:113-21.

Sikorski ZE, Kolakowska A, eds. Chemical and Functional Properties of Food Lipids. Boca Raton: CRC Press; 2002.

Sönmez M, Türk G, Yüce A. The effect of ascorbic acid supplementation on sperm quality, lipid peroxidation and testosterone levels of male Wistar rats. Theriogenology. 2005;63:2063-72. PMID: 15823361 DOI: $10.1016 / j$.theriogenology.2004.10.003
Sönmez M, Yüce A, Türk G. The protective effects of melatonin and Vitamin $E$ on antioxidant enzyme activities and epididymal sperm characteristics of homocysteine treated male rats. Reprod Toxicol. 2007;23:226-31. PMID: 17178211 DOI: $10.1016 /$ j.reprotox.2006.11.003

Tehrani FR, Rashidi H, Azizi F. The prevalence of idiopathic hirsutism and polycystic ovary syndrome in the Tehran Lipid and Glucose Study. Reprod Biol Endocrinol. 2011;9:144. PMID: 22044512 DOI: 10.1186/1477-7827-9-144

Wahle KW, Heys SD, Rotondo D. Conjugated linoleic acids: are they beneficial or detrimental to health? Prog Lipid Res. 2004;43:553-87. PMID: 15522764 DOI: $10.1016 / j$. plipres.2004.08.002

Wang ET, Calderon-Margalit R, Cedars MI, Daviglus ML, Merkin SS, Schreiner PJ, Sternfeld B, Wellons M, Schwartz SM, Lewis CE, Williams OD, Siscovick DS, Bibbins-Domingo $\mathrm{K}$. Polycystic ovary syndrome and risk for long-term diabetes and dyslipidemia. Obstet Gynecol. 2011;117:6-13. PMID: 21173640 DOI: 10.1097/AOG.0b013e31820209bb

Yildirim B, Sabir N, Kaleli B. Relation of intra-abdominal fat distribution to metabolic disorders in nonobese patients with polycystic ovary syndrome. Fertil Steril. 2003;79:1358-64. PMID: 12798883 DOI: 10.1016/S0015-0282(03)00265-6 